\title{
Causes of Urban Migration in Bangladesh: Evidence from the Urban Health Survey
}

\begin{abstract}
Mass migration is increasing urban populations globally. One country where urban migration is significantly increasing is Bangladesh, where systematic research will explore the reasons for urban migration in order to devise policies in this area, including maintaining the balance of urban-rural developments. This study used the Urban Health Survey (UHS) 2013 to ascertain the reasons for urban migration in large divisional cities in Bangladesh. The 2013 survey examined the differences between male and female migration, alongside any significant socio-demographic factors that might contribute to their motivation for moving to the city. The survey revealed that a majority of women (64.8\%) migrated for family purposes, for example, joining husbands or in-laws, or parents/children. However, in recent years, female migrants have been involved in income generating activities mostly due to a recent garment-making boom in Dhaka and its suburbs. A higher proportion of men (85.3\%) moved to urban areas for work-related reasons: searching for new jobs, better income, or transfer in services. Among the sample in this study, $77 \%$ of the respondents $(79.3 \%$ female and $73.5 \%$ male) migrated from villages. This migration mostly centered on Dhaka, the capital city of Bangladesh, where $68.1 \%$ of the total study sample migrated followed by $15.7 \%$ who went to Chittagong. The results indicate that the contemporary urban-centred economic policy in Bangladesh might require revision to accommodate the increased migrants from rural areas.

Keywords: Urban migration, Rural-urban migration, Urbanization, Dhaka, Bangladesh, South-Asia
\end{abstract}

\section{Introduction}

Bangladesh reached the rank of a low-middle income country in 2014 (Feldman, 2015; World Bank, 2016). As the country grew economically, there was a significant increase in urban migration of Bangladesh over the last decade (Hossain, 2001; Rouf and Jahan, 2007). The urban population exploded from 14.1 million in 1981 to 35 million in 2005 and reached 53.1 million in 2014 United 
Nations, 2014). Migration is considered a primary contributor to the fast urban growth alongside highly urban-centralized development, rapid urban industrialization, and temporary in-migration during lean seasons (Harpham, 2009; Seto et al., 2010; Farhana et al., 2012; Bryan et al., 2014). The scenario in Bangladesh warrants an investigation on the reasons for such rapid urban migration to aid policy makers to balance urban-rural developments. The Urban Health Survey 2013 Angeles et al., 2013) was used in this study to explore the major causes of rural-urban migration for both males and females in Bangladesh, and assess the significant sociodemographic factors contributing to the causes through inequalities between urban and rural areas. These factors lead to a discussion on how the scarcity of work in rural areas pushes residents to migrate and urbancentered industrialization pulls migrants to metropolitan areas where a greater variety of is are regularly generated.

Urban migration is a much-discussed topic in both economics and demography, particularly focusing on the sustainable development of a country (Lall and Selod, 2006; Lu, 2010). These macro-level affects are results of individual migrations, signifying an urban-rural gap as well as socioeconomic changes for an individual, due to a shift in residence. For example, Young (2013) showed that $40 \%$ of the mean country inequality, along with the cross-country variation, could be explained by the urban-rural gap, which reflects the increasing difference in living standards between urban and rural areas (Thu Le and Booth, 2014; Brueckner and Lall, 2015). In developed countries, internal migration generally determines population growth or decline in cities/towns (Buch et al., 2014). However, developing nations, for example, Bangladesh, experience a lasting change in demography primarily because of the rural to urban migration and subsequent shift from an agro-centred rural economy to an industry-based urban economy (Seto, 2011; Christiaensen and Todo, 2014; Tacoli et al., 2015).

A number of factors such as lack of a social safety net, scarcity of heterogeneous job openings in the traditionally slow rural economy, and/or sudden natural disasters often result in a mass shift in population from rural to urban areas in low and middle-income countries (Simini et al., 2012; Nguyen et al., 2015). There is no in-depth study of the causes of such migration in Bangladesh, a deficiency that is explored in this paper. For example, rural-urban migration accounted for half of the urban growth in African countries during the 1960s through to the 1990s, with large variations among nations (World Health Organization, 2000; Barrios et al., 2006). Rural-urban migration in South-Asia is accounted for the expansion of cities into peripheral areas due to 
urban focused investment as well as rural poverty, lack of resources for rural entrepreneurs, and substandard village life (Ebrahim et al., 2010). For example, Dhaka city, the capital of Bangladesh, experienced a mass influx of migrants early 90s that has quickly populated the city (Mohit, 2012; Hossain, 2013).

Although there have been several studies on urban migration in Bangladesh, they have rarely focused on the reasons for recent mass urban migration from rural areas. These studies primarily focused on public health aspects, particularly accessibility to health facilities, a comparison between sociodemographic status of the two areas (urban and rural), environmental factors, and changes in the health dynamics of migrants, for example Body Mass Index (BMI) Mullick and Goodman, 2005; Islam and Azad, 2008; Streatfield and Karar, 2008; Khan et al., 2009). Geographical pushpull factors that balance the attracting and repelling elements of migration and economic models that are driven by financial differences among localities, are frequently referred to in order to understand the internal migration system in Bangladesh (Marshall and Rahman, 2013). Giani (2006) stated that employment opportunity is one of the main reasons for rural to major city migration in the country (Deshingkar and Grimm, 2005) along with 'bright city lights' ("Dhaka means Taka" / money) (Ishtiaque and Ullah, 2013). Using a data set of 500 residents of Dhaka City, Hossain (2005) listed natural disasters (e.g., river erosion) and accompanying family members as potential reasons for migration. However, these studies were confined to a few cities (mainly Dhaka) with limited samples. A study based on district-wide data from two censuses (1991 and 2011) found three particular causes of migration: economic conditions, quality of public services and environmental challenges, although they did not investigate the contribution of household factors for these causes (Marshall and Rahman, 2013). This study used a nationwide household survey data set to summarize the dominant causes of urban migration and the possible contributions of relevant sociodemographic factors. 


\section{Theoretical framework}

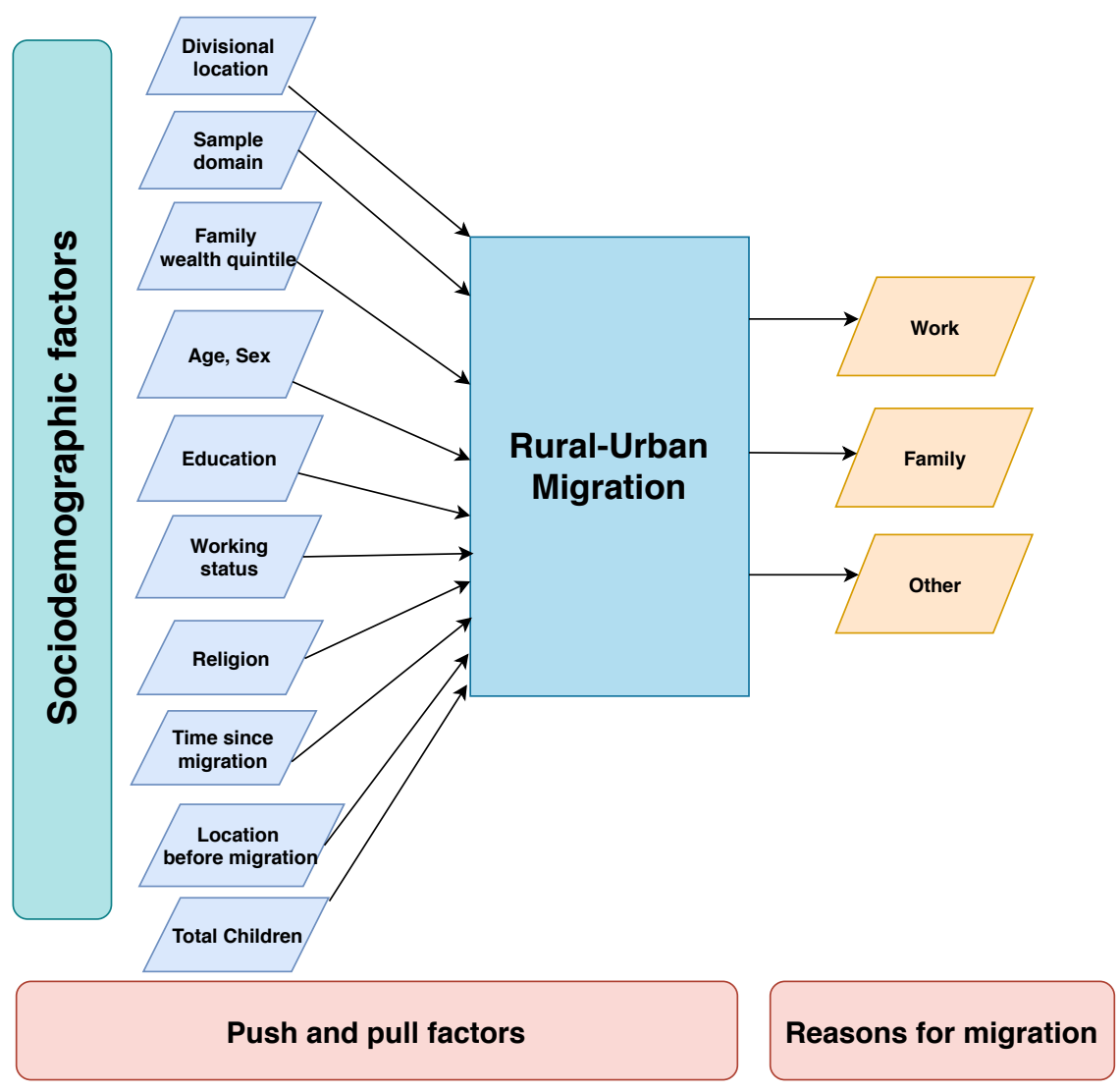

Figure 1: A theoretical framework of the study: the effect of push and pull factors leading to migrations

The objective of the study was to investigate the reasons for urban migration in Bangladesh. Furthermore, the associations of various sociodemographic factors with these reasons would be analyzed to identify the vulnerable groups who are more likely to migrate than other groups. The hypothesis of the study was that some of these sociodemographic issues induce the residents in rural areas of Bangladesh to migrate to big cities.

There are several working theories to explain migration: Neoclassical Macro theory for labor migration and Network theory for migration due to inter-personal ties (Massey et al., 1993; Boyd and Grieco, 2003: Hagen-Zanker, 2008). Both labor migration and social ties seem to be an apparent fit to the migrations in Bangladesh as males primarily tend to look for work and females migrate generally with families. These push and pull factors have been discussed in relation to migrations in other countries like China (Qiang, 2003), Lithuania (Kazlauskienè and Rinkevičius, 2006) and developing nations (Lall and Selod, 2006). Based on these factors and available data 
indicators, this study has chosen the factors mentioned in Figure 1 and analyzed the migration scenario in Bangladesh.

\section{Methods}

\section{Data Overview}

The 2013 Bangladesh Urban Health Survey (UHS) is a national representative survey on urban residents conducted by the National Institute of Population Research and Training (NIPORT), Measure Evaluation, University of North Carolina at Chapel Hill, USA, and the International Centre for Diarrhoeal Disease Research, Bangladesh (ICDDR,B). The survey data was collected separately on females, males, households, and communities along with a verbal investigation in 2013, which was a follow up of a 2006 survey (NIPORT, icddr,b, and UNC-Chapel Hill, 2013). The data were collected from three strata: a) slum areas of city corporations; b) non-slum areas of city corporations; and c) other district municipalities or large towns with over 45,000 residents.

A three-stage stratified sampling method was applied for the data collection. Firstly, 450 Mohallas, the smallest administrative areas of Bangladesh, were selected from city corporations and 184 Mohallas selected from other towns. Secondly, two non-slum clusters and one slum cluster were randomly selected from each Mohalla. Thirdly, following household listing, a number of households were randomly sampled from each cluster. All married woman aged between 14-49, and all married man aged 15-54 were sampled for the final survey. Please refer to NIPORT, icddr,b, and UNC-Chapel Hill (2013) for detailed survey sampling and definition of key terms like slum, non-slum, and Mohalla.

This study used female and male data sets separately, and then later combined them for an overall analysis. The data of migrants were extracted by omitting those respondents who had lived in the sample (urban) areas since birth. The respondents with missing data were removed as well. The final sample size was 15,387 (female), 5,126 (male) and 20,513 (combined female and male).

\section{Sociodemographic factors}

The socioeconomic factors available in the data sets that were relevant for this study were: divisions - the highest administrative area of Bangladesh; sample domain (city corporation (nonslum area); city corporation (slum area); other urban areas); wealth quintile - five-scale based index on household assets quantified by principal component approach, age of the respondents; 
education (none, primary, secondary, higher); working status (yes, no); religion (Islam, others); time since lived in the current urban residence (less than 2 years, 2-4 years, 5+ years); place of previous residence (urban/sub-urban, village), and total number of children. The only author defined category was length of time since moving here, based on the technical report of Jamil et al. (2014). The 'urban/sub-urban' category of the variable 'place of previous residence' included city corporations, district towns, other towns and abroad, and the other category was 'village' that included all the residents from rural areas.

\section{Outcome variable}

As the objective of the study was to assess the various reasons for migration, the reasons for respondents' migration from UHS 2013 were considered as the outcome variable. The specific migration reasons and their subsequent sample size are detailed in Figure 2. However, for the benefit of the analysis, these reasons were collapsed into three categories: a) work, b) family, and c) other.

\section{Statistical analysis}

Bivariate analysis Agresti and Kateri, 2011) was conducted to provide an overview of the frequency distributions of the sociodemographic factors on the outcome variable: the reasons for migration. A chi-square test determined the strength of each bivariate dependence. Following these analyses, the Multinomial Logistic regression Model (Upton, 2016) was fitted to the threecategory reasons of migration with the sociodemographic factors. It provided the effect size and the direction of associations of the covariates with the migration reasons. Considering the reasons were not ordinal in nature, the multinomial logistic model was a suitable option. The analyses were conducted in $R$ (version 3.4.1).

While generally a p-value of 0.05 is considered the threshold of significant association, this study followed the recommendation of Benjamin et al. (2017) to use a threshold of 0.005 for new discoveries. Therefore, the covariates were interpreted as significant only when the p-values were less or equal to 0.005 and consistent with the relevant confidence interval. 


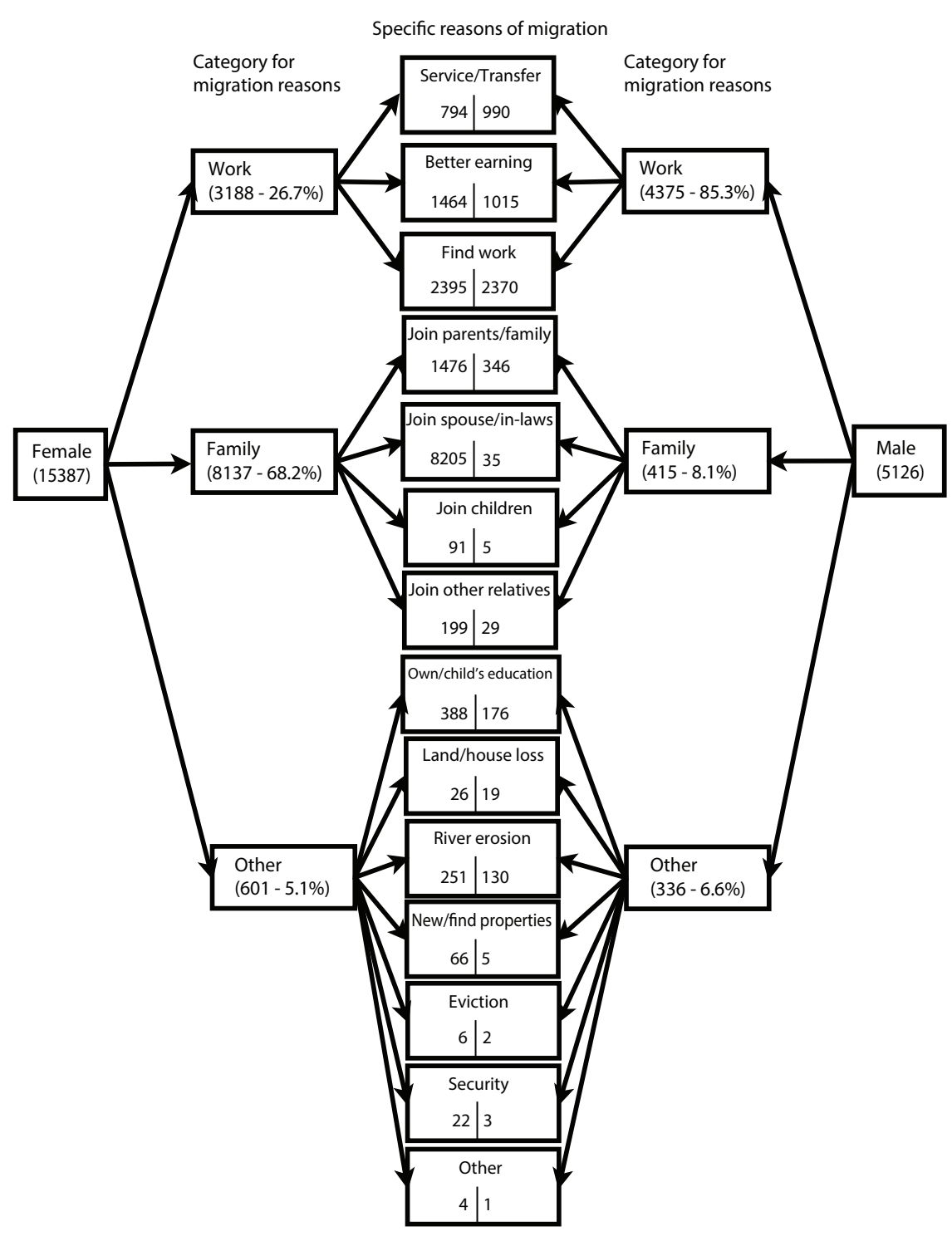

Figure 2: The categorization of the various reasons of migration into three levels, and their sample sizes

\section{Results}

In the combined sample, nearly $72 \%$ of the respondents migrated more than five years ago; of these, $71.8 \%$ were female and rest were male. Most of the women (64.8\%) migrated for family purposes e.g., joining husband or in-laws, or parents/children; whereas a higher proportion of men (85.3\%) moved to urban areas for work related ventures: in search of new jobs, better incomes or service transfers. Comparatively fewer males migrated for family or other reasons. Around $27 \%$ of women living in urban residences for over five years reported work as their main reason for migration, whereas of the women who migrated recently ( $<2$ years), around $40 \%$ of them moved 
for work purposes. This may indicate a change in the migration patterns for women, but year-wise data were required to reach a definite conclusion.

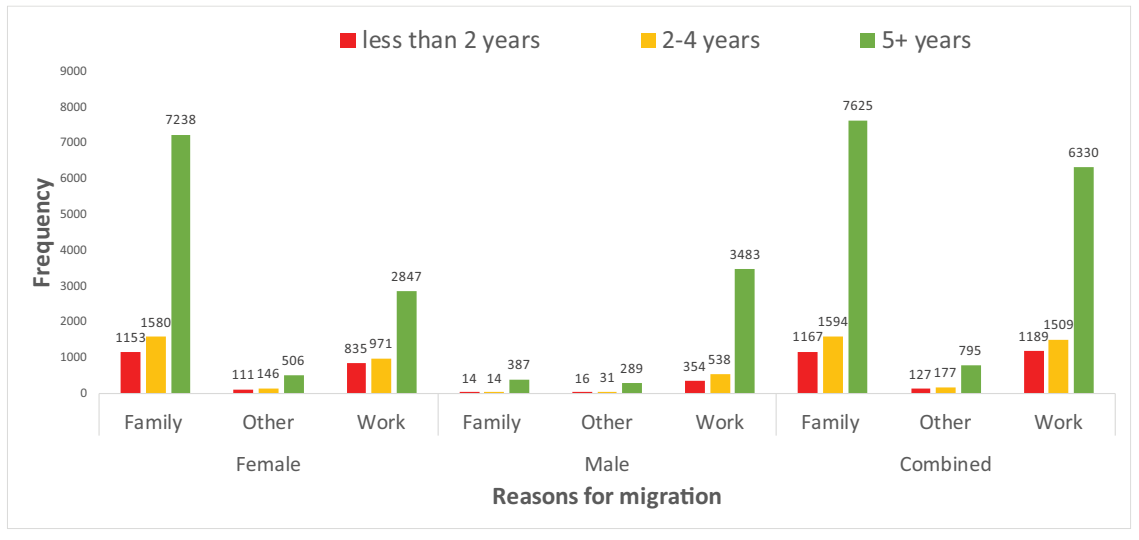

Figure 3: Grouped bar plots displaying the time the migrants have spent in the urban areas based on their reasons of migration

Around $77 \%$ of the respondents $(79.3 \%$ female and $73.5 \%$ male) were from villages indicating significant rural-urban migration (Table 1). Migration was mostly centered to Dhaka where $68.1 \%$ of the total study sample migrated, followed by $15.7 \%$ who went to Chittagong. Most of the males from three sample domains migrated for work $(81.5 \%, 88.7 \%$ and $81.9 \%)$, whereas $39.6 \%$ of females in slum areas migrated for work, with over $50 \%$ of the women moving for/with their families. In all three cases (female, male, and combined), the respondents from lower wealth quintiles had work related reasons for migration, which was generally replaced by family reasons in richer quintiles. However, such patterns were not noticeable in the bivariate relationship between education and causes of migration. Overall, $26.7 \%$ of women migrated for work but $36.6 \%$ of all women were currently working. On the other hand, $98.6 \%$ of the male migrants had been in income generating activities over the previous 12 months. The average age of the migrants was 29-35 years for both genders, with men's mean age slightly higher than that of the women, and the average number of children in a family was below three. All the sociodemographic factors, apart from religion and place of previous residence in the male sample, showed significant association $(\mathrm{p}$-value $<0.001)$ with reasons for migration.

Results from the bivariate analysis were substantiated through the multinomial regression. Compared with family reasons, men were 5.42 times more likely to migrate for other reasons and 10.37 times more likely to migrate (significant at $0.01 \%$ ) for work-related reasons than women 
(Combined model in Table 2). In the female sample, compared to Barisal, the likelihood of migrating to any divisional cities was less for work or other causes than for family reasons. Compared to the non-slum areas of city corporations, women were $20 \%$ less likely to migrate to districts or large towns for work than for family related reasons but this was not significant for males. Males were $48 \%$ less likely to move to other urban areas than to non-slum areas for reasons other than family related. It is evident that migration for work was common for both males and females from the poorest families. For example, females from the richest households were nearly $60 \%$ less likely to migrate for work than family compared to the poorest females. Compared to the illiterate, the more highly educated were $14 \%$ less likely (female) and 1.89 times more likely (male) to migrate for work than for family reasons. Working status was only significant for currently working women who were more likely to move for work (3.52 times) or other reasons (2.05 times) than family related reasons compared to those who were unemployed. Migrants living in their current residences for over 5 years were significantly less likely to have moved for work or other reasons than for family compared to the recent ( $<2$ years) migrants (both male and female in Table 2). 
Table 1: Bivariate analysis of the sociodemographic factors fitted with the reasons for migration based of gender

\begin{tabular}{|c|c|c|c|c|c|c|c|c|c|}
\hline \multirow[b]{3}{*}{ Sociodemographic factors } & \multicolumn{3}{|c|}{ Female } & \multicolumn{4}{|c|}{ Male } & \multicolumn{2}{|l|}{ Combined } \\
\hline & \multirow[b]{2}{*}{ Family } & \multirow[b]{2}{*}{ Other } & \multicolumn{5}{|c|}{ Reasons for migration - N (\%) } & \multirow[b]{2}{*}{ Other } & \multirow[b]{2}{*}{ Work } \\
\hline & & & Work & Family & Other & Work & Family & & \\
\hline \multicolumn{10}{|l|}{ Division } \\
\hline Barisal & $217(67.6 \%)$ & $35(10.9 \%)$ & $69(21.5 \%)$ & $14(17.3 \%)$ & $4(4.9 \%)$ & $63(77.8 \%)$ & $231(57.5 \%)$ & $39(9.7 \%)$ & $132(32.8 \%)$ \\
\hline Chittagong & $1545(62.7 \%)$ & $118(4.8 \%)$ & $802(32.5 \%)$ & $69(9.2 \%)$ & $37(4.9 \%)$ & $643(85.8 \%)$ & $1614(50.2 \%)$ & $155(4.8 \%)$ & $1445(45 \%)$ \\
\hline Dhaka & $6152(61.3 \%)$ & $535(5.2 \%)$ & $3513(34.4 \%)$ & $245(6.5 \%)$ & $254(6.7 \%)$ & $3271(86.8 \%)$ & $6397(45.8 \%)$ & $789(5.6 \%)$ & $6784(48.6 \%)$ \\
\hline Khulna & $662(92.5 \%)$ & $14(2 \%)$ & $40(5.6 \%)$ & $45(21.5 \%)$ & $16(7.7 \%)$ & $148(70.8 \%)$ & $707(76.4 \%)$ & $30(3.2 \%)$ & $188(20.3 \%)$ \\
\hline Rajshahi & $717(89.1 \%)$ & $29(3.6 \%)$ & $59(7.3 \%)$ & $21(15.8 \%)$ & $14(10.5 \%)$ & $98(73.7 \%)$ & $738(78.7 \%)$ & $43(4.6 \%)$ & $153(16.7 \%)$ \\
\hline Rangpur & $402(85 \%)$ & $15(3.2 \%)$ & $56(11.8 \%)$ & $9(15.3 \%)$ & $6(10.2 \%)^{*}$ & $44(74.6 \%)$ & $411(77.3 \%)$ & $21(3.9 \%)$ & $100(18.8 \%)$ \\
\hline Sylhet & $276(67.8 \%)$ & $17(4.2 \%)$ & $114(28 \%)$ & $12(9.6 \%)$ & $5(4 \%)$ & $108(86.4 \%)$ & $288(54.1 \%)$ & $22(4.1 \%)$ & $222(41.7 \%)$ \\
\hline P-value & $<0.001$ & & & $<0.001$ & & & $<0.001$ & & \\
\hline \multicolumn{10}{|l|}{ Sample domain } \\
\hline City corporation (non-slum area) & $2597(68.9 \%)$ & $259(6.9 \%)$ & $912(24.2 \%)$ & $123(8 \%)$ & $160(10.4 \%)$ & $1250(81.5 \%)$ & $2720(51.3 \%)$ & $419(7.9 \%)$ & $2162(40.8 \%)$ \\
\hline City corporation (Slum area) & $4110(56.5 \%)$ & $281(3.9 \%)$ & $2886(39.6 \%)$ & $187(7 \%)$ & $116(4.3 \%)$ & $2380(88.7 \%)$ & $4297(43.1 \%)$ & $397(4 \%)$ & $5266(52.9 \%)$ \\
\hline Other urban areas & $3264(75.2 \%)$ & $223(5.1 \%)$ & $855(19.7 \%)$ & $105(11.5 \%)$ & $60(6.6 \%)$ & $745(81.9 \%)$ & $3369(64.1 \%)$ & $283(5.4 \%)$ & $1600(30.5 \%)$ \\
\hline P-value & $<0.001$ & & & $<0.001$ & & & $<0.001$ & & \\
\hline \multicolumn{10}{|l|}{ Wealth quintile } \\
\hline Poorest & $2368(54.9 \%)$ & $151(3.5 \%)$ & $1798(41.6 \%)$ & $103(6.6 \%)$ & $74(4.7 \%)$ & $1381(88.6 \%)$ & $2471(42.1 \%)$ & $225(3.8 \%)$ & $3179(54.1 \%)$ \\
\hline Poorer & $2430(60.2 \%)$ & $132(3.3 \%)$ & $1473(36.5 \%)$ & $112(8 \%)$ & $58(4.2 \%)$ & $1224(87.8 \%)$ & $2542(46.8 \%)$ & $190(3.5 \%)$ & $2697(49.7 \%)$ \\
\hline Middle & $2116(71.1 \%)$ & $130(4.4 \%)$ & $728(24.5 \%)$ & $86(8.9 \%)$ & $49(5.1 \%)$ & $829(86 \%)$ & $2202(55.9 \%)$ & $179(4.5 \%)$ & $1557(39.5 \%)$ \\
\hline Richer & $1684(75.7 \%)$ & $168(7.6 \%)$ & $372(16.7 \%)$ & $69(10.5 \%)$ & $69(10.5)$ & $520(79 \%)$ & $1753(60.8 \%)$ & $237(8.2 \%)$ & $892(31 \%)$ \\
\hline Richest & $1373(74.7 \%)$ & $182(9.9 \%)$ & $282(15.4 \%)$ & $45(8.2 \%)$ & $86(15.6 \%)$ & $421(76.3 \%)$ & $1418(59.4 \%)$ & $268(11.2 \%)$ & $703(29.4 \%)$ \\
\hline P-value & $<0.001$ & & & $<0.001$ & & & $<0.001$ & & \\
\hline Age in years ${ }^{\mathrm{a}}$ & 29.73 & 33.77 & 31.04 & 35.19 & 38.47 & 36.75 & 29.95 & 35.21 & 33.81 \\
\hline \multicolumn{10}{|l|}{ Education } \\
\hline None & $1834(53 \%)$ & $162(4.7 \%)$ & $1465(42.3 \%)$ & $82(7.5 \%)$ & $64(5.9 \%)$ & $943(86.6 \%)$ & $1916(42.1 \%)$ & $226(5 \%)$ & $2408(52.9 \%)$ \\
\hline Primary & $2736(60.1 \%)$ & $171(3.8 \%)$ & $1648(36.2 \%)$ & $126(8.4 \%)$ & $51(3.4 \%)$ & $1321(88.2 \%)$ & $2862(47.3 \%)$ & $222(3.7 \%)$ & $2969(49.1 \%)$ \\
\hline Secondary & $4029(74 \%)$ & $225(4.1 \%)$ & $1193(21.9 \%)$ & $133(8.7 \%)$ & $51(3.4 \%)$ & $1336(87.9 \%)$ & $4162(59.7 \%)$ & $276(4 \%)$ & $2529(36.3 \%)$ \\
\hline Higher & $1372(71.3 \%)$ & $20.5(10.7 \%)$ & $347(18 \%)$ & $74(7.3 \%)$ & $170(16.7 \%)$ & $775(76.1 \%)$ & $1446(49.1 \%)$ & $375(12.7 \%)$ & $1122(38.1 \%)$ \\
\hline $\mathrm{P}$-value & $<0.001$ & & & $<0.001$ & & & $<0.001$ & & \\
\hline \multicolumn{10}{|l|}{ Working status } \\
\hline No & $8156(74 \%)$ & $549(5 \%)$ & $2317(21 \%)$ & $8(11.4 \%)^{*}$ & $15(21.4 \%)$ & $47(67.1 \%)$ & $8164(73.6 \%)$ & $564(5.1 \%)$ & $2364(21.3 \%)$ \\
\hline Yes & $1815(41.6 \%)$ & $214(4.9 \%)$ & $2336(53.5 \%)$ & $407(8 \%)$ & $321(6.3 \%)$ & $4328(85.6 \%)$ & $2222(23.6 \%)$ & $535(5.7 \%)$ & $6664(70.7 \%)$ \\
\hline P-value & $<0.001$ & & & $<0.001$ & & & $<0.001$ & & \\
\hline \multicolumn{10}{|l|}{ Religion } \\
\hline Islam & $9138(63.8 \%)$ & $710(5 \%)$ & $4469(31.2 \%)$ & $394(8.1 \%)$ & $311(6.4 \%)$ & $4163(85.5 \%)$ & $9532(49.7 \%)$ & $1021(5.3 \%)$ & $8632(45 \%)$ \\
\hline Others & $833(77.9 \%)$ & $53(5 \%)$ & $184(17.2 \%)$ & $21(8.1 \%)$ & $25(9.7 \%)$ & $212(82.2 \%)$ & $854(64.3 \%)$ & $78(5.9 \%)$ & $396(29.8 \%)$ \\
\hline P-value & $<0.001$ & & & $<0.001$ & & & $<0.001$ & & \\
\hline \multicolumn{10}{|l|}{ Time since lived here } \\
\hline less than 2 years & $1153(54.9 \%)$ & $111(5.3 \%)$ & $835(39.8 \%)$ & $14(3.6 \%)$ & $16(4.2 \%)$ & $354(92.2 \%)$ & $1167(47 \%)$ & $127(5.1 \%)$ & $1189(47.9 \%)$ \\
\hline $2-4$ years & $1580(58.6 \%)$ & $146(5.4 \%)$ & $971(36 \%)$ & $14(2.4 \%)$ & $31(5.3 \%)$ & $538(92.3 \%)$ & $1594(48.6 \%)$ & $177(5.4 \%)$ & $1509(46 \%)$ \\
\hline $5+$ years & $7238(68.3 \%)$ & $506(4.8 \%)$ & $2847(26.9 \%)$ & $387(9.3 \%)$ & $289(6.9 \%)$ & $3483(83.7 \%)$ & $7625(51.7 \%)$ & $795(5.4 \%)$ & $6330(42.9 \%)$ \\
\hline P-value & $<0.001$ & & & $<0.001$ & & & $<0.001$ & & \\
\hline \multicolumn{10}{|c|}{ Place of residence before migration } \\
\hline Urban/sub-urban & $2039(64 \%)$ & $205(6.4 \%)$ & $943(29.6 \%)$ & $113(8.3 \%)$ & $83(6.1 \%)$ & $1162(85.6 \%)$ & $2152(47.3 \%)$ & $288(6.3 \%)$ & $2105(46.3 \%)$ \\
\hline Village & $7932(65 \%)$ & $558(4.6 \%)$ & $3710(8 \%)$ & $302(72.8 \%)$ & $253(6.7 \%)$ & $3213(85.3 \%)$ & $8234(51.6 \%)$ & $811(5.1 \%)$ & $6923(43.4 \%)$ \\
\hline $\mathrm{P}$-value & $<0.001$ & & & 0.712 & & & $<0.001$ & & \\
\hline Total Children $^{\mathrm{a}}$ & 1.86 & 2.30 & 2.16 & 1.76 & 1.94 & 2.08 & 1.86 & 2.19 & 2.12 \\
\hline \multicolumn{10}{|l|}{ Sex } \\
\hline Female & & & & & & & $9971(64.8 \%)$ & $763(5.0 \%)$ & $4653(30.2 \%)$ \\
\hline Male & & & & & & & $415(8.1 \%)$ & $336(6.6 \%)$ & $4375(85.3 \%)$ \\
\hline $\mathrm{P}$-value & & & & & & & $<0.001$ & & \\
\hline
\end{tabular}

${ }^{a}$ Mean of the continuous variables have been tabulated(fior each reason of migration, ${ }^{*}$ The expected cell size is below 5 , which compromises the chi-square test assumption. 


\section{Discussion}

According to the results, around $68 \%$ of the migrants from rural areas were living in Dhaka City, which is now one of the fastest growing megacities in the world (Islam et al., 2014; Pramanik and Stathakis, 2016). Around $75.5 \%$ of the total females who migrated for work reasons moved to Dhaka, with $17.2 \%$ moving to Chittagong; $61.7 \%$ of females migrating for family reasons went to Dhaka and $15.5 \%$ to Chittagong. Nearly twice the number of females migrated to Dhaka for family reasons compared to work. $73.5 \%$ of males migrated to Dhaka with $86.48 \%$ of them moving for work reasons. This mass migration actively contributed to population growth in Dhaka (Debnath and Amin, 2016) and gave rise to urban complexities including increased criminal activities, conspicuous drug addiction, heightened sexually transmitted disease rates, and high suicide rates (Jahan, 2012, Haque and Rana, 2014; Kamruzzaman and Hakim, 2015; McClair et al., 2017). The growing work opportunities in Dhaka and Chittagong and in their suburbs, is primarily due to industrialization, including the boom of export-oriented garment companies that is attracting both male and female migrants alongside their family members (Muhammad, 2011; Muzzini and Aparicio, 2013; Ahmed et al., 2014a). 
Table 2: Multinomial regression fitted to work and other reasons in reference with family reasons for migration to the sociodemographic factors

\begin{tabular}{|c|c|c|c|c|c|c|c|c|c|c|c|c|}
\hline \multirow{3}{*}{ Covariates } & \multicolumn{4}{|c|}{ Female respondents } & \multicolumn{4}{|c|}{ Male respondents } & \multicolumn{4}{|c|}{ Combined } \\
\hline & \multicolumn{2}{|c|}{ For other reasons } & \multicolumn{2}{|c|}{ For work } & \multicolumn{2}{|c|}{ For other reasons } & \multicolumn{2}{|c|}{ For work } & \multicolumn{2}{|c|}{ For other reasons } & \multicolumn{2}{|l|}{ For work } \\
\hline & $\begin{array}{l}\text { Odds } \\
(95 \% \mathrm{CI})\end{array}$ & P-value & $\begin{array}{l}\text { Odds } \\
(95 \% \text { CI })\end{array}$ & P-value & $\begin{array}{l}\text { Odds } \\
(95 \% \mathrm{CI})\end{array}$ & P-value & $\begin{array}{l}\text { Odds } \\
(95 \% \text { CI })\end{array}$ & P-value & $\begin{array}{l}\text { Odds } \\
(95 \% \mathrm{CI})\end{array}$ & P-value & $\begin{array}{l}\text { Odds } \\
(95 \% \mathrm{CI})\end{array}$ & P-value \\
\hline \multicolumn{13}{|l|}{ Division (ref: Barisal) } \\
\hline Chittagong & $0.51(0.33,0.77)$ & 0.002 & $0.81(0.56,1.16)$ & 0.2493 & $3.30(0.98,11.07)$ & 0.054 & $1.30(0.36,4.63)$ & 0.687 & $0.67(0.45,0.99)$ & 0.045 & $1.36(1.05,1.77)$ & 0.021 \\
\hline Dhaka & $0.60(0.41,0.88)$ & 0.009 & $0.23(0.14,0.39)$ & $<0.001$ & $6.15(1.94,19.52)$ & 0.002 & $2.43(1.27,4.66)$ & 0.008 & $0.81(0.56,1.16)$ & 0.249 & $1.43(1.11,1.84)$ & 0.006 \\
\hline Khulna & $0.14(0.07,0.27)$ & $<0.001$ & $0.32(0.2,0.52)$ & $<0.001$ & $1.78(0.50,6.41)$ & 0.376 & $3.86(2.08,7.14)$ & $<0.001$ & $0.23(0.14,0.39)$ & $<0.001$ & $0.34(0.25,0.47)$ & $<0.001$ \\
\hline Rajshahi & $0.26(0.15,0.44)$ & $<0.001$ & $0.30(0.17,0.53)$ & $<0.001$ & $2.23(0.58,8.52)$ & 0.241 & $0.88(0.44,1.76)$ & 0.716 & $0.32(0.2,0.52)$ & $<0.001$ & $0.41(0.30,0.57)$ & $<0.001$ \\
\hline Rangpur & $0.22(0.12,0.43)$ & $<0.001$ & $0.45(0.26,0.81)$ & 0.007 & $2.82(0.59,13.53)$ & 0.196 & $1.41(0.65,3.07)$ & 0.385 & $0.30(0.17,0.53)$ & $<0.001$ & $0.43(0.30,0.61)$ & $<0.001$ \\
\hline Sylhet & $0.38(0.20,0.71)$ & 0.002 & $0.67(0.45,0.99)$ & 0.0449 & $2.04(0.43,9.71)$ & 0.372 & $1.36(0.52,3.52)$ & 0.529 & $0.45(0.26,0.81)$ & 0.007 & $1.05(0.76,1.46)$ & 0.753 \\
\hline \multicolumn{13}{|c|}{ Sample domain (ref: City corporation (non-slum area)) } \\
\hline City corporation (Slum) & $1.02(0.81,1.29)$ & 0.842 & $1.00(0.89,1.12)$ & 0.974 & $0.79(0.52,1.21)$ & 0.276 & $1.06(0.80,1.41)$ & 0.685 & $0.89(0.73,1.08)$ & 0.226 & $0.94(0.85,1.04)$ & 0.247 \\
\hline Other urban areas & $1.05(0.85,1.30)$ & 0.620 & $0.80(0.70,0.90)$ & $<0.001$ & $0.52(0.33,0.81)$ & 0.004 & $0.70(0.51,0.95)$ & 0.021 & $0.85(0.71,1.02)$ & 0.075 & $0.74(0.66,0.82)$ & $<0.001$ \\
\hline \multicolumn{13}{|c|}{ Wealth quintile (ref: Poorest) } \\
\hline Poorer & $0.90(0.70,1.15)$ & 0.383 & $0.89(0.80,0.98)$ & 0.021 & $0.63(0.4,0.99)$ & 0.045 & $0.79(0.59,1.06)$ & 0.115 & $0.82(0.67,1.01)$ & 0.069 & $0.87(0.79,0.95)$ & 0.003 \\
\hline Middle & $1.05(0.81,1.36)$ & 0.729 & $0.63(0.56,0.71)$ & $<0.001$ & $0.53(0.32,0.88)$ & 0.015 & $0.70(0.51,0.97)$ & 0.032 & $0.87(0.69,1.08)$ & 0.209 & $0.66(0.59,0.73)$ & $<0.001$ \\
\hline Richer & $1.64(1.23,2.19)$ & $<0.001$ & $0.53(0.45,0.63)$ & $<0.001$ & $0.55(0.31,0.99)$ & 0.047 & $0.51(0.35,0.76)$ & 0.001 & $1.23(0.96,1.58)$ & 0.099 & $0.55(0.48,0.63)$ & $<0.001$ \\
\hline Richest & $1.59(1.14,2.22)$ & 0.006 & $0.41(0.33,0.50)$ & $<0.001$ & $0.56(0.29,1.09)$ & 0.087 & $0.49(0.30,0.80)$ & 0.004 & $1.06(0.80,1.41)$ & 0.671 & $0.38(0.32,0.45)$ & $<0.001$ \\
\hline Age (continuous) & $1.06(1.04,1.07)$ & $<0.001$ & $1.04(1.03,1.04)$ & $<0.001$ & $1.04(1.02,1.07)$ & $<0.001$ & $1.03(1.01,1.05)$ & $<0.001$ & $1.07(1.06,1.08)$ & $<0.001$ & $1.07(1.06,1.07)$ & $<0.001$ \\
\hline \multicolumn{13}{|c|}{ Education (ref: no education) } \\
\hline Primary & $0.95(0.75,1.20)$ & 0.675 & $0.98(0.89,1.09)$ & 0.776 & $0.63(0.39,1.01)$ & 0.056 & $1.10(0.81,1.49)$ & 0.548 & $0.88(0.72,1.08)$ & 0.231 & $1.13(1.03,1.25)$ & 0.012 \\
\hline Secondary & $0.88(0.68,1.14)$ & 0.327 & $0.74(0.66,0.84)$ & $<0.001$ & $0.72(0.44,1.20)$ & 0.208 & $1.36(0.99,1.87)$ & 0.061 & $0.87(0.70,1.08)$ & 0.207 & $1.04(0.93,1.15)$ & 0.500 \\
\hline Higher & $1.79(1.31,2.43)$ & $<0.001$ & $0.86(0.71,1.03)$ & 0.104 & $4.62(2.62,8.16)$ & $<0.001$ & $1.89(1.24,2.87)$ & 0.003 & $2.43(1.88,3.13)$ & $<0.001$ & $1.36(1.17,1.58)$ & $<0.001$ \\
\hline \multicolumn{13}{|l|}{ Working status (ref: No) } \\
\hline Yes & $2.05(1.71,2.45)$ & $<0.001$ & $3.52(3.24,3.83)$ & $<0.001$ & $0.58(0.23,1.46)$ & 0.243 & $2.20(0.99,4.89)$ & 0.053 & $3.14(2.73,3.61)$ & $<0.001$ & $8.35(7.76,8.98)$ & $<0.001$ \\
\hline \multicolumn{13}{|l|}{ Religion (ref: Islam) } \\
\hline Others & $0.77(0.57,1.04)$ & 0.091 & $0.68(0.57,0.81)$ & $<0.001$ & $1.17(0.62,2.22)$ & 0.621 & $1.19(0.74,1.93)$ & 0.476 & $0.76(0.59,0.99)$ & 0.039 & $0.67(0.57,0.78)$ & $<0.001$ \\
\hline \multicolumn{13}{|c|}{ Time since lived here (ref: less than 2 years) } \\
\hline 2-4 years & $0.80(0.61,1.04)$ & 0.096 & $0.82(0.71,0.93)$ & 0.003 & $1.82(0.69,4.80)$ & 0.228 & $1.58(0.74,3.38)$ & 0.240 & $0.85(0.66,1.09)$ & 0.204 & $0.83(0.73,0.95)$ & 0.006 \\
\hline $5+$ years & $0.36(0.29,0.46)$ & $<0.001$ & $0.40(0.35,0.45)$ & $<0.001$ & $0.50(0.23,1.06)$ & 0.069 & $0.30(0.17,0.52)$ & $<0.001$ & $0.44(0.35,0.55)$ & $<0.001$ & $0.41(0.37,0.46)$ & $<0.001$ \\
\hline \multicolumn{13}{|c|}{ Place of residence before migration (ref: Urban/sub-urban) } \\
\hline Village & $0.84(0.70,1.00)$ & 0.053 & $0.83(0.75,0.91)$ & $<0.001$ & $1.41(1.00,1.99)$ & 0.051 & $1.01(0.80,1.28)$ & 0.926 & $0.93(0.80,1.08)$ & 0.337 & $0.82(0.75,0.89)$ & $<0.001$ \\
\hline $\begin{array}{l}\text { Total Children } \\
\text { (continuous) }\end{array}$ & $1.16(1.09,1.25)$ & $<0.001$ & $1.08(1.04,1.12)$ & $<0.001$ & $1.05(0.90,1.22)$ & 0.558 & $1.14(1.02,1.26)$ & 0.019 & $1.06(1.00,1.13)$ & 0.044 & $1.00(0.96,1.03)$ & 0.827 \\
\hline \multicolumn{13}{|l|}{ Sex (ref: Female) } \\
\hline Male & & & & & & & & & $5.42(4.37,6.72)$ & $<0.001$ & $10.37(9.12,11.79)$ & $<0.001$ \\
\hline
\end{tabular}

A migrant's economic status is associated with a reason for moving to an urban area, and it adds to the urban economy (Haggblade et al., 2010; Santos, 2017). The poor in rural areas, who cannot find work there, tend to search for jobs in urban areas where the economy is dynamic and more jobs are regularly generated. In the study data, $70.3 \%$ of poor females (below middle class) migrated for work reasons, $48.1 \%$ migrated for family and $37.1 \%$ for other reasons. Only $14.1 \%$ of females from rich families (above middle class) migrated for work. However, the difference was not so distinct for men $-88.6 \%$ of male migrants from the poorest households migrated for work, compared to $76.3 \%$ from the richest households. Among the male migrants who came looking for work, 59.6\% belonged to poorer (below middle class) families. Given the compromised economic status of the migrants, they tended to live in the budget suburbs or urban slums and so these 
settlements grew rapidly in Dhaka City (Rahaman and Ahmed, 2016; Ishtiaque and Mahmud, 2017). This study found that almost half (52.3\%) of the men migrated to the slum areas of the city corporation, of whom $88.7 \%$ migrated for work. These align with the global migration trend of the poor moving to a megacity in the hope of a higher standard of living (Rana, 2011; Mberu et al., 2017; Randolph and Naik, 2017).

Only those respondents with the highest level of education had a significant difference among their reasons for migration compared to the illiterate (Table 2). Among the women who migrated for work, nearly $70 \%$ of them had received primary or no education. Only $12.5 \%$ of females in the sample were highly educated and $71.3 \%$ of these migrated for family reasons, whereas $53 \%$ of the uneducated migrated for family reasons; $43.5 \%$ of male migrants were either illiterate or had primary education, however, except for highly educated males, 85\% or more males from all the educational categories migrated in search of work or higher earnings. The influx of unskilled male laborers joining the urban economy generally took the low-skilled jobs such as construction work, cleaning services of the city corporation or pulling rickshaws/vans (Ahmed et al., 2014b). The educated and skilled generally found jobs in their locality. Having said that, the tertiary educational institutions are in the major cities with most of the private Universities in Dhaka City (Monem and Muhammad, 2010). This would encourage the skilled workforce to migrate to (or never leave) metropolitan areas, where they might find value for their education and expertise Sharma and Zaman (2013).

Job opportunities are higher in urban areas compared to the slower economies in villages where cash income is mostly seasonal (Berg and Shahe Emran, 2017). Although many people migrate for better incomes, only half $(50.2 \%)$ of the women who migrated for work had been involved in income generating activities in the previous 12 months. However, $98.6 \%$ of male migrants had worked in income generating activities during the previous 12 months, and among the unemployed, $67.1 \%$ had migrated for work. There is a distinctive pattern between men and women looking for work and finding it, one that is rather common in the Bangladeshi patriarchal society where men are the primary earners in the family (Parveen, 2007; Karim et al., 2016; Biswas et al., 2017). According to the study data, $18.2 \%$ of women who primarily migrated for family purposes were currently working. This illustrates a shift in the social paradigm as women were sdirectly involved in the economy.

This change is further accentuated by the fact that the proportion of females recently (less 
than two years) migrating for work has increased $(39.8 \%)$ compared to those who migrated 5 years or more ago $(26.9 \%)$. Despite the timing of migration, most of the male migration is due to work related reasons. The dynamic urban economy and recent female education stipend programs introduced by the government have encouraged women to join the workforce and change their socioeconomic status (Hahn et al., 2015; VanderEnde et al., 2015). The recent rapid growth in the ready-made garment industry in Bangladesh, located in urban areas or adjacent suburbs, has enabled the employment of over 4 million women. This has helped to delay early marriage and childbirth, and increased school enrollment so ultimately paving the way for women's empowerment (Heath and Mobarak, 2015; Rahman and Siddiqui, 2015).

The overarching results from this study indicate that male migrants move to Dhaka or other metropolitan areas mainly in search of work, and accompanying eventually females join the workforce unless they initially migrated for work (Akhter and Bauer, 2014). These contribute to urban-centered industrialization, where significant number of jobs are regularly generated, which are more often filled by the migrants. Unless a decentralized planned economy is put into place, such migration will continue to increase population density in the urban domains. Cities like Dhaka will suffer from this growing population in terms of health concerns in the urban slums, lack of green vegetation across the city, unaffordable housing and shortage of sanitation services Al Jaber et al., 2014; Adams et al., 2015, Brueckner and Lall, 2015; Morshed et al., 2017). Existing policies do not reflect the changed urban discourses, and this extreme centralization (Dhaka contains $37 \%$ of the total urban population) invites more migrants, resulting in extreme inequality within the urban sphere (Rahman, 2014, Ahmed et al., 2014b; Ferdaush, 2015).

This study was limited to a small number of issues that could pave the way for future studies. Firstly, this study considered migrants from both urban and rural areas that could be refined to rural-urban migration to attain results that are more specific. Secondly, the survey weight or clustering was not accounted for in the multinomial model. Current $R$ package survey does not have the scope of fitting multinomial models (Lumley, 2011). Thirdly, the data did not provide detail on the type of work migrants came to find; that would have aided to better understand their lack of scope for particular professions that were unavailable in rural areas. Finally, year wide migration could be extracted from the data set to decipher the patterns of migration over the years, which could be preferable for a policy-based study outlet. More importantly, future studies could design experiments based on the sociodemographic factors that were found significant in this 
study, which might reveal a causal link between rural-urban migration and the relevant vulnerable cohort.

An extension of this current work could be to run a decomposition analysis between the seasonal migrants and permanent migrants. It might provide socioeconomic differences between the two groups and their reasons for migration. Another possible option is to compare the sociodemographic differences between the migrants and permanent residents living there since birth. It might indicate some of the hurdles migrants initially endure. It was quite surprising that the current dataset found that only $2 \%$ of the migrants moved due to natural calamities, which is lower than expected. However, Bangladesh is not necessarily as environmentally challenged as it was decades ago, and data from only coastal zones or northern Monga-affected areas (seasonal drought leading to multiple years of no agricultural output) places the environment as a major cause of migration (Marshall and Rahman, 2013). Other studies that focused on vulnerable cohort theorizing on the push-pull factor found that the environment was a likely cause of migration (Gray and Mueller, 2012; Penning-Rowsell et al., 2013). Future studies could compare these results with the country's overall internal migration.

\section{Conclusion}

This study conducted an analysis on the recent data set of urban residents in Bangladesh. Current urban growth in this country is supplemented by continuous large migration from rural areas and is one of the primary reasons why Dhaka, the capital city, is evolving into a megacity. This study found that $77.8 \%$ of migrants moved from villages to urban neighborhoods. The majority of women migrated for family reasons, mostly accompanying their husbands or in-laws, whereas male migrants went in search of jobs or better earning sources. However, more recent female migrants are increasingly involved in the workforce due to the increase in the garment sector in Dhaka and its suburbs. Education, economic status of families, religion and place of previous residence contributed to the causes of migration. The current urban-centred policies in Bangladesh encourage more in-migration due to higher investment in these areas and access to public services. However, it is taking a toll on the urban environment and is increasing the slum areas. A holistic urban strategy is required to address the needs of the migrants and to accommodate them in proper residences. As environmental causes become less important and most migrants move for a better lifestyle, policymakers in Bangladesh could focus on the proportional distribution of industrial 
investment and public services that might help alleviate population congestion in its major cities.

\section{References}

Adams, A. M., Islam, R., and Ahmed, T. (2015). Who serves the urban poor? a geospatial and descriptive analysis of health services in slum settlements in dhaka, bangladesh. Health policy and planning, 30(suppl_1):i32-i45.

Agresti, A. and Kateri, M. (2011). Categorical data analysis. In International encyclopedia of statistical science, pages 206-208. Springer.

Ahmed, F. Z., Greenleaf, A., and Sacks, A. (2014a). The paradox of export growth in areas of weak governance: The case of the ready made garment sector in bangladesh. World Development, 56:258-271.

Ahmed, S. J., Nahiduzzaman, K. M., and Bramley, G. (2014b). From a town to a megacity: 400 years of growth. In Dhaka Megacity, pages 23-43. Springer.

Akhter, S. and Bauer, S. (2014). Household level determinants of rural-urban migration in bangladesh. International Journal of Social, Human Science and Engineering, 8(1):24-27.

Al Jaber, S., Ghosh, A. K., and Mahmud, M. S. (2014). Using time series of satellite images to detect vegetation cover change in dhaka city. Journal of Geographic Information System, 6(06):653.

Angeles, G., Al-Sabir, A., Lance, P., Buckner, B., Streatfield, P., Karar, Z., et al. (2013). Bangladesh urban health survey (uhs) 2013. National Institute of Population Research and Training (NIPORT); International Centre for Diarrhoeal Disease Research, Bangladesh (icddr,b); MEASURE Evaluation, 2016. doi:10.15139/S3/12274, UNC Dataverse, V1.

Barrios, S., Bertinelli, L., and Strobl, E. (2006). Climatic change and rural-urban migration: The case of subsaharan africa. Journal of Urban Economics, 60(3):357-371.

Benjamin, D. J., Berger, J. O., Johannesson, M., Nosek, B. A., Wagenmakers, E.-J., Berk, R., Bollen, K. A., Brembs, B., Brown, L., Camerer, C., et al. (2017). Redefine statistical significance. Nature Human Behaviour, page 1.

Berg, C. N. and Shahe Emran, M. (2017). Microfinance and vulnerability to seasonal famine in a rural economy: Evidence from monga in bangladesh.

Biswas, R. K., Rahman, N., Kabir, E., and Raihan, F. (2017). Womens opinion on the justification of physical spousal violence: A quantitative approach to model the most vulnerable households in bangladesh. PloS one, 12(11):e0187884.

Boyd, M. and Grieco, E. (2003). Women and migration: incorporating gender into international migration theory. Migration information source, 1(35):28. 
Brueckner, J. K. and Lall, S. (2015). Cities in developing countries: Fueled by rural-urban migration, lacking in tenure security, and short of affordable housing. Handbook of Regional and Urban Economics, 5:1399-1455.

Bryan, G., Chowdhury, S., and Mobarak, A. M. (2014). Underinvestment in a profitable technology: The case of seasonal migration in bangladesh. Econometrica, 82(5):1671-1748.

Buch, T., Hamann, S., Niebuhr, A., and Rossen, A. (2014). What makes cities attractive? the determinants of urban labour migration in germany. Urban Studies, 51(9):1960-1978.

Christiaensen, L. and Todo, Y. (2014). Poverty reduction during the rural-urban transformation-the role of the missing middle. World Development, 63:43-58.

Debnath, R. and Amin, A. N. (2016). A geographic information system-based logical urban growth model for predicting spatial growth of an urban area. Environment and Planning B: Planning and Design, 43(3):580-597.

Deshingkar, P. and Grimm, S. (2005). Internal migration and development: a global perspective. Number 19. United Nations Publications.

Ebrahim, S., Kinra, S., Bowen, L., Andersen, E., Ben-Shlomo, Y., Lyngdoh, T., Ramakrishnan, L., Ahuja, R., Joshi, P., Das, S. M., et al. (2010). The effect of rural-to-urban migration on obesity and diabetes in india: a cross-sectional study. PLoS medicine, 7(4):e1000268.

Farhana, K. M., Rahman, S. A., and Rahman, M. (2012). Factors of migration in urban bangladesh: An empirical study of poor migrants in rahshahi city.

Feldman, S. (2015). Bangladesh in 2014: Illusive democracy. Asian Survey, 55(1):67-74.

Ferdaush, J. (2015). The Urbanization of Dhaka City and the Sustainable Urban Development in Bangladesh. PhD thesis, Savannah State University.

Giani, L. (2006). Migration and education: Child migrants in bangladesh. Sussex Migration WorkingPaperno, 33.

Gray, C. L. and Mueller, V. (2012). Natural disasters and population mobility in bangladesh. Proceedings of the National Academy of Sciences, 109(16):6000-6005.

Hagen-Zanker, J. (2008). Why do people migrate? a review of the theoretical literature.

Haggblade, S., Hazell, P., and Reardon, T. (2010). The rural non-farm economy: Prospects for growth and poverty reduction. World Development, 38(10):1429-1441.

Hahn, Y., Islam, A., Nuzhat, K., Smyth, R., Yang, H.-S., et al. (2015). Education, marriage and fertility: Long-term evidence from a female stipend program in bangladesh. Melbourne: Monash University. 
Haque, R. and Rana, E. A. (2014). Urban youth delinquency: Proliferation of criminal gangs and neighbourhood violence in dhaka, bangladesh.

Harpham, T. (2009). Urban health in developing countries: what do we know and where do we go? Health $\mathcal{E}$ place, 15(1):107-116.

Heath, R. and Mobarak, A. M. (2015). Manufacturing growth and the lives of bangladeshi women. Journal of Development Economics, 115:1-15.

Hossain, M. (2001). Rural-urban migration in bangladesh: a micro-level study. In Brazil IUSSP conference. August, pages $20-24$.

Hossain, S. (2005). Poverty, household strategies and coping with urban life: examining livelihood frameworkin dhaka city, bangladesh. Bangladesh e-journal of Sociology, 2(1):1-8.

Hossain, S. (2013). Migration, urbanization and poverty in dhaka, bangladesh. Journal of the Asiatic Society of Bangladesh (Hum.), 58(2):369-382.

Ishtiaque, A. and Mahmud, M. S. (2017). Migration objectives and their fulfillment: A micro study of the ruralurban migrants of the slums of dhaka city. Geografia-Malaysian Journal of Society and Space, 7(4).

Ishtiaque, A. and Ullah, M. S. (2013). The influence of factors of migration on the migration status of rural-urban migrants in dhaka, bangladesh. Human Geographies, 7(2):45.

Islam, M. M. and Azad, K. M. A. K. (2008). Rural-urban migration and child survival in urban bangladesh: Are the urban migrants and poor disadvantaged? Journal of biosocial science, 40(1):83-96.

Islam, M. S., Rana, M. M. P., and Ahmed, R. (2014). Environmental perception during rapid population growth and urbanization: a case study of dhaka city. Environment, development and sustainability, 16(2):443-453.

Jahan, M. (2012). Impact of rural urban migration on physical and social environment: the case of dhaka city. International Journal of Development and Sustainability, 1(2):186-194.

Jamil, K., Streatfield, P. K., Arifeen, S., Angeles, G., Rahman, M., Ahsan, K. Z., Kamal, N., Rashida-E-Ijdi, Chakraborty, N., and Bhuiya, A. (2014). Bangladesh urban health survey 2013: Preliminary results. National Institute of Population Research and Training (NIPORT), MEASURE Evaluation, UNC-Chapel Hill, International Centre for Diarrhoeal Disease Resaearch Bangladesh (ICDDRB).

Kamruzzaman, M. and Hakim, M. A. (2015). Child criminalization at slum areas in dhaka city. American Journal of Psychology and Cognitive Science, 1(4):107-111.

Karim, K. R., Emmelin, M., Lindberg, L., and Wamala, S. (2016). Gender and women development initiatives in bangladesh: a study of rural mother center. Social work in public health, 31(5):369-386. 
Kazlauskienè, A. and Rinkevičius, L. (2006). Lithuanian brain drain causes: Push and pull factors. Engineering economics, 46(1):27-37.

Khan, M. M., Krämer, A., et al. (2009). Factors associated with being underweight, overweight and obese among ever-married non-pregnant urban women in bangladesh. Singapore medical journal, 50(8):804.

Lall, S. V. and Selod, H. (2006). Rural-urban migration in developing countries: A survey of theoretical predictions and empirical findings, volume 3915. World Bank Publications.

Lu, Y. (2010). Rural-urban migration and health: Evidence from longitudinal data in indonesia. Social science $\mathcal{E}^{3}$ medicine, 70(3):412-419.

Lumley, T. (2011). Complex surveys: a guide to analysis using $R$, volume 565. John Wiley \& Sons.

Marshall, R. and Rahman, S. (2013). Internal migration in bangladesh: character, drivers and policy issues. United Nations Development Programme (UNDP), New York.

Massey, D. S., Arango, J., Hugo, G., Kouaouci, A., Pellegrino, A., and Taylor, J. E. (1993). Theories of international migration: A review and appraisal. Population and development review, 19(3):431-466.

Mberu, B., Béguy, D., and Ezeh, A. C. (2017). Internal migration, urbanization and slums in sub-saharan africa. In Africa's Population: In Search of a Demographic Dividend, pages 315-332. Springer.

McClair, T. L., Hossain, T., Sultana, N., Burnett-Zieman, B., Yam, E. A., Hossain, S., Yasmin, R., Sadiq, N., Decker, M. R., and Ahmed, S. (2017). Paying for sex by young men who live on the streets in dhaka city: Compounded sexual risk in a vulnerable migrant community. Journal of Adolescent Health, 60(2):S29-S34.

Mohit, M. A. (2012). Bastee settlements of dhaka city, bangladesh: a review of policy approaches and challenges ahead. Procedia-Social and Behavioral Sciences, 36:611-622.

Monem, M. and Muhammad, H. (2010). Higher education in bangladesh: Status, issues and prospects. Pakistan Journal of Social Sciences (PJSS), 30(2).

Morshed, N., Yorke, C., and Zhang, Q. (2017). Urban expansion pattern and land use dynamics in dhaka, 1989-2014. The Professional Geographer, pages 1-16.

Muhammad, A. (2011). Wealth and deprivation: Ready-made garments industry in bangladesh. Economic and Political Weekly, pages 23-27.

Mullick, M. S. I. and Goodman, R. (2005). The prevalence of psychiatric disorders among 5-10 year olds in rural, urban and slum areas in bangladesh. Social psychiatry and psychiatric epidemiology, 40(8):663-671.

Muzzini, E. and Aparicio, G. (2013). Urban growth and spatial transition in Nepal: An initial assessment. World Bank Publications. 
Nguyen, L. D., Raabe, K., and Grote, U. (2015). Rural-urban migration, household vulnerability, and welfare in vietnam. World Development, 71:79-93.

NIPORT, icddr,b, and UNC-Chapel Hill (2013). Bangladesh urban health survey 2013 final report. available in: https://www.measureevaluation.org/resources/publications/tr-15-117, funded by USAID.

Parveen, S. (2007). Gender awareness of rural women in bangladesh. Journal of International Women's Studies, 9(1):253.

Penning-Rowsell, E. C., Sultana, P., and Thompson, P. M. (2013). The last resort? population movement in response to climate-related hazards in bangladesh. Environmental science $\mathcal{E}$ policy, 27:S44-S59.

Pramanik, M. M. A. and Stathakis, D. (2016). Forecasting urban sprawl in dhaka city of bangladesh. Environment and Planning B: Planning and Design, 43(4):756-771.

Qiang, L. (2003). An analysis of push and pull factors in the migration of rural workers in china [j]. Social Sciences In China, 1:125-136.

Rahaman, M. M. and Ahmed, T. S. (2016). Affordable water pricing for slums dwellers in dhaka metropolitan area: the case of three slums. J Water Resour Eng Manag, 3(1):15-33.

Rahman, H. Z. (2014). Urbanization in bangladesh: challenges and priorities. In Bangladesh Economists Forum. June, pages 21-22.

Rahman, M. H. and Siddiqui, S. A. (2015). Female rmg worker: economic contribution in bangladesh. Int J Sci Res Publ, 5:9.

Rana, M. M. P. (2011). Urbanization and sustainability: challenges and strategies for sustainable urban development in bangladesh. Environment, Development and Sustainability, 13(1):237-256.

Randolph, G. F. and Naik, M. (2017). An analysis of migrant-intensityin india and indonesia: Seeing internal migration patterns through a place-based lens. Environment and Urbanization ASIA, 8(1):40-58.

Rouf, M. A. and Jahan, S. (2007). Spatial and temporal patterns of urbanization in bangladesh. Urbanization in Bangladesh: patterns, issues and approaches to planning. Bangladesh Institute of Planners, Dhaka, pages 1-24.

Santos, M. (2017). The shared space: the two circuits of the urban economy in underdeveloped countries. Routledge.

Seto, K. C. (2011). Exploring the dynamics of migration to mega-delta cities in asia and africa: Contemporary drivers and future scenarios. Global Environmental Change, 21:S94-S107.

Seto, K. C., Sánchez-Rodríguez, R., and Fragkias, M. (2010). The new geography of contemporary urbanization and the environment. Annual review of environment and resources, 35:167-194. 
Sharma, M. and Zaman, H. (2013). Who migrates overseas and is it worth their while?: an assessment of household survey data from bangladesh. The Journal of Developing Areas, 47(1):281-302.

Simini, F., González, M. C., Maritan, A., and Barabási, A.-L. (2012). A universal model for mobility and migration patterns. Nature, 484(7392):96-100.

Streatfield, P. K. and Karar, Z. A. (2008). Population challenges for bangladesh in the coming decades. Journal of health, population, and nutrition, 26(3):261.

Tacoli, C., McGranahan, G., and Satterthwaite, D. (2015). Urbanisation, rural-urban migration and urban poverty. IIED London.

Thu Le, H. and Booth, A. L. (2014). Inequality in vietnamese urban-rural living standards, 1993-2006. Review of Income and Wealth, 60(4):862-886.

United Nations (2014). World urbanization prospects: The 2014 revision. Population Division, United Nations. ISBN 978-92-1-151517-6.

Upton, G. J. (2016). Categorical Data Analysis by Example. John Wiley \& Sons.

VanderEnde, K. E., Sibley, L. M., Cheong, Y. F., Naved, R. T., and Yount, K. M. (2015). Community economic status and intimate partner violence against women in bangladesh: compositional or contextual effects? Violence against women, 21(6):679-699.

World Bank (2016). Helping Bangladesh Reach Middle Income Country Status. http://www.worldbank. org/en/news/feature/2016/04/07/World_Bank_Group_s_New_Country_Partnership_Framework_helps_ Bangladesh_Reach_Middle_Income_Country_Status. [Online; accessed 28-11-2017].

World Health Organization (2000). The world health report 2000: health systems: improving performance. World Health Organization.

Young, A. (2013). Inequality, the urban-rural gap, and migration. The Quarterly Journal of Economics, 128(4):17271785. 